\title{
Textiles and Jewelry at Fag el-Gamous
}

Joyce Smith

Kerry Muhlestein

Brigham Young University - Provo, kerry_muhlestein@byu.edu

Brian Christensen

Follow this and additional works at: https://scholarsarchive.byu.edu/facpub

Part of the Ancient, Medieval, Renaissance and Baroque Art and Architecture Commons

\section{Original Publication Citation}

"Textiles and Jewelry at Fag el-Gamous," in Excavations at Fag el-Gamous and the Seila Pyramid, Kerry Muhlestein, editor in chief, Krystal V. L. Pierce and Bethany Jesnen, eds., Harvard Egyptological Studies vol. 7. (Leiden: Brill, 2020), 186-206.

\section{BYU ScholarsArchive Citation}

Smith, Joyce; Muhlestein, Kerry; and Christensen, Brian, "Textiles and Jewelry at Fag el-Gamous" (2020). Faculty Publications. 3564.

https://scholarsarchive.byu.edu/facpub/3564

This Book Chapter is brought to you for free and open access by BYU ScholarsArchive. It has been accepted for inclusion in Faculty Publications by an authorized administrator of BYU ScholarsArchive. For more information, please contact ellen_amatangelo@byu.edu. 
Textiles and Jewelry at Fag el-Gamous

Joyce Smith, Kerry Muhlestein and Brian Christensen

Published as "Textiles and Jewelry at Fag el-Gamous," in Excavations at Fag el-Gamous and the Seila Pyramid, Kerry Muhlestein, editor in chief, Krystal V. L. Pierce and Bethany Jesnen, eds., Harvard Egyptological Studies vol. 7. (Leiden: Brill, 2020), 186-206. Because of the size of the file, pictures are not included in this version.

[page 186]

Elsewhere in this volume we discuss extensively the burial practices of the common man as represented in the Fag el-Gamous sand cemetery. While these burials must represent the common, or poorer, people of the area due to their large numbers, they are remarkable in regards to the amount of resources used for a common burial. ${ }^{1}$ The two most frequently used types of goods associated with these burials, and probably the most expensive, are textiles and jewelry. In order to better understand these burials and the requisite resources marshaled by the deceased during their life and their loved ones after their death, this paper explores a few case studies of burial textiles and jewelry. By better understanding these two elements, we can more fully understand funerary culture of the area as a whole. For those who are interested, explanations of some terms specific to textiles are placed in footnotes.

\section{The Weave of Burial Shrouds}

"Textiles and clothing are perhaps the most significant markers of human existence," and say something about the identity of the person. ${ }^{2}$ Of course the textiles we examine speak of their identity in death, or a hoped for identity in the afterlife, but they still say something about the self-identity of those who were buried at Fag el-Gamous. Linen is by far the most common material from which textiles for either the living or dead were made in Egypt, ${ }^{3}$ and form the vast majority of textiles found in the cemetery. While we have found many burials at Fag el-Gamous that have intricate patterns and vibrant colors in their burial textiles, the majority have been much more plain. Most publications about textiles from Egypt have focused, understandably, on the most vibrant and intricate examples. These are the kinds of pieces that were brought [page 187] back from Egypt and made their way to museums and university collections where they were later carefully studied and published. ${ }^{4}$ In contrast, here we wish to focus on the more common burial. Thus we will first present information about more mundane and common fabric largely devoid of colorful patterns. Patterns are made by adding extra or colored lines to either the warp

\footnotetext{
${ }^{1}$ See the article on "Death of a Poor Man" in this volume.

2 Jochen Sokoly, "Textiles and Identity," in Finbarr Barry Flood and Gülru Necipoğlu, eds. A Companion to Islamic Art and Architecture (New York: John Wiley \& Sons Inc., 2017), 275; and Christina Riggs, Unwrapping Ancient Egypt (New York: Bloomsbury Academic: 2014), 120.

${ }^{3}$ See Riggs, Unwrapping Ancient Egypt, 109-111.

${ }^{4}$ For example, see László Török, Coptic Antiquities II, Textiles (Rome: L’Erma di Brethschneider, 1993). This is an excellent publication of a number of very high quality and spectacular textiles.
} 
or weft threads ${ }^{5}$ of a textile. The type of textile most frequently found in the burials at Fag elGamous is a rather coarse, basket weave ${ }^{6}$ linen textile with a repeated pattern of ribs ${ }^{7}$ designated by our analysts as the X-2-X-2-X pattern. ("X" represents the rib). The rib structures are formed by inserting additional weft threads per shot. ${ }^{8}$ If there are a total of 5 threads forming the rib, it would be designated as " $5 X$ "; 3 threads in the rib would be " $3 X$ " etc. The number " 2 " represents the two shots of regular weave between the ribs. An X-2-X-2-X rib pattern is designated by the repetition of a rib, followed by two shots, then another rib, two shots, and a third rib. This rib pattern is generally repeated throughout the entire cloth at intervals ranging from 4 to 15 centimeters between the rib pattern structure. It may be a product that was manufactured specifically for use in burying the dead, possibly produced from local weaving workshops.

At Fag el-Gamous, fabrics used in life could become a shroud or covering for the dead, such as when well-worn tunics and or sheets of linen with evidence of patching and mending are found as burial coverings. At the same time, there are also numerous examples of newly woven pieces of linen, many of which are of the basket weave, 3-rib pattern. These textiles show no evidence of wear or use prior to padding and wrapping the deceased. Even under a microscope no fraying is visible. Since almost any use at all creates microscopic fraying, this indicates that these textiles were used only in death.

Often at Fag el-Gamous, fine white-bleached linen, plain (tabby) ${ }^{9}$ weave shrouds are found held in place with red and white (or un-dyed) woven ribbon as the outer-most burial covering. It is also common to find several layers of [page 188] coarse basket weave (or extended weave ${ }^{10}$ shrouds, made of un-dyed linen with the repeated pattern of weft ribs, beneath the outer white, plain weave shroud. These large pieces of cloth were newly constructed and seem to have been made specifically to be used at the time of burial. At Fag el-Gamous the earlier burials tend to employ more used and worn textiles for burial, but as time went on the trend turned more and more towards being buried in new textiles, presumably created for the purpose of covering the dead. While body fluids are responsible for textile deterioration on the torso of the body, the parts of shrouds wrapping the upper body and lower legs and feet are often still clean and supple. This same type of ribbed linen fabric is also found folded and used to provide additional padding and shaping around the body and is often found in the folded layers of face bundles. Torn strips of linen, 2-3 cm wide, are used in the same manner as the red and white ribbons, to bind or wrap around shrouds, particularly interior shroud layers. Often, there is no selvedge on the shroud itself, but the torn strips do have one selvedge edge. These strips often

\footnotetext{
${ }^{5}$ Warps are the long threads held in place on a loom, wefts are the threads woven into and around the warp threads

${ }^{6}$ See the article on basket weave in this volume.

${ }^{7}$ Ribs are raised lines across the width of the fabric.

${ }^{8} \mathrm{~A}$ shot is a single pass of the weft thread woven through the lengthwise warp threads across the width of the fabric.

${ }^{9}$ Gillian Vogelsang-Eastwood, "Textiles," in Ancient Egyptian Materials and Technology, Paul T.

Nicholson and Ian Shaw, eds. (Cambridge: Cambridge University Press, 2000), 274.

${ }^{10}$ Ibid.
} 
have an X-2-X-2-X pattern matching the pattern of the shroud, indicating that the torn, binding strips were taken from the same or similar piece of cloth.

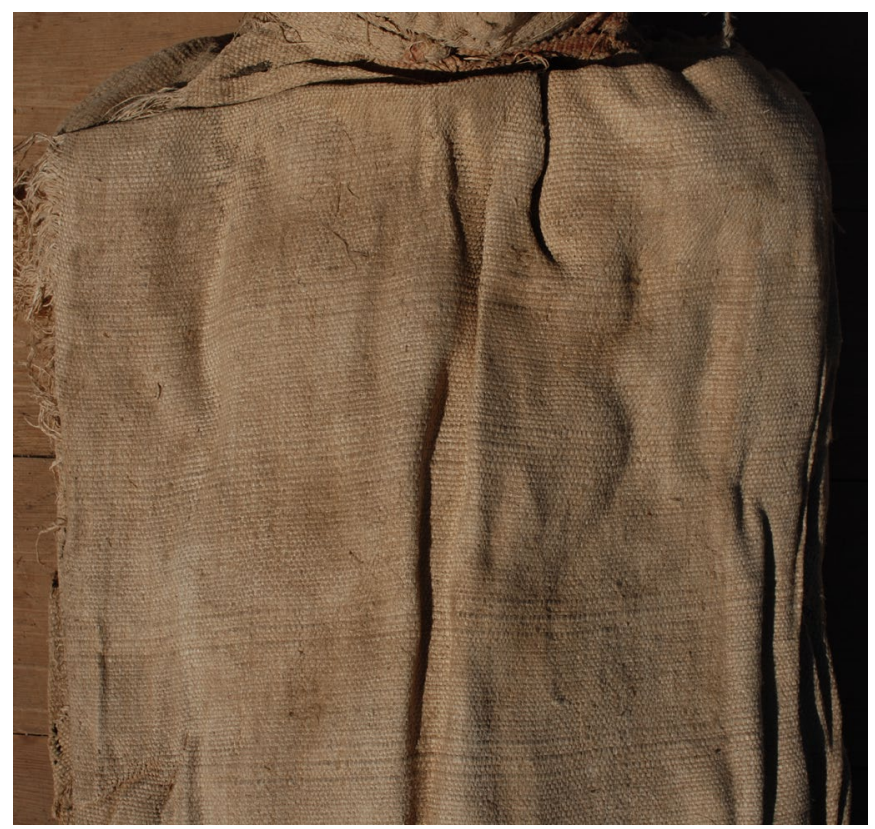

Figure 8.1: an example of a plain weave, ribbed burial textile. Photography by Joyce Smith

[page 189]

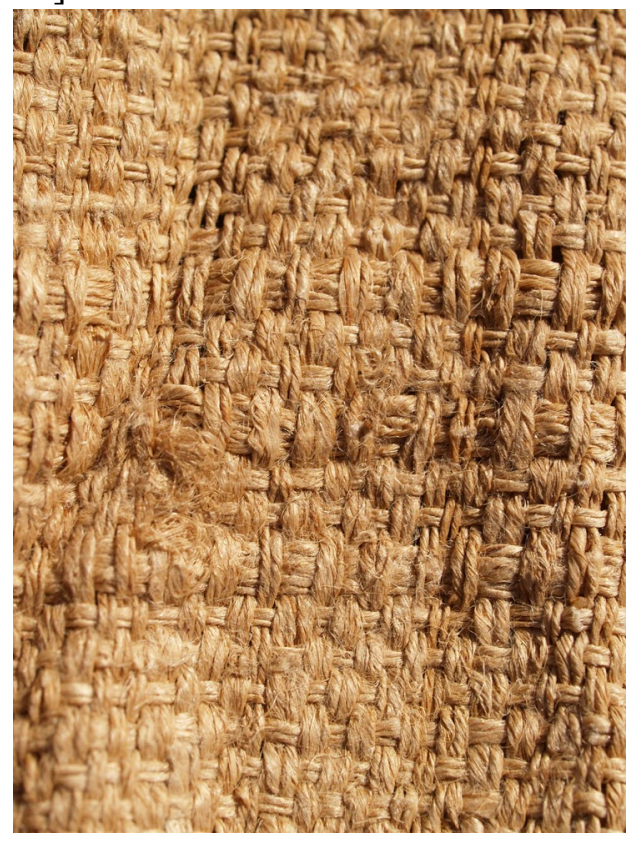

Figure 8.2: A closeup of ribs with six thread (6X) within basket weave. Photograph by Joyce Smith

These textiles are best understood by looking at specific examples. The aforementioned patterns are evident in specific samples of textiles from burials studied during the 2010 season. It 
should be noted that nothing was included with any of these burials that allows us to determine a date.

From the area 190/200 N 30/40 E, excavated in 2009, Burial NE \#22 was located at a depth of $110 \mathrm{~cm}$. The third layer of textiles (from the outside) was un-dyed linen, basket weave, measuring $35 \mathrm{~cm}$ in the warp direction, including a $14 \mathrm{~cm}$ fringe, and $52 \mathrm{~cm}$ in the weft direction. Thread count was 22 warp and [page 190] 10 weft, single ply threads, S twist, soft spun, and of medium thickness. There was a $4 \mathrm{X}-2-4 \mathrm{X}-2-4 \mathrm{X}$ weft rib pattern that was repeated every $6 \mathrm{~cm}$. Torn linen strips were used as binding and had a rib pattern similar to the shroud.

Burial NE \#56 was also from 2009 and analyzed during the 2010 season. It was linen basket weave cloth with ribs. It measured $58 \mathrm{~cm}$ in the warp direction, $81 \mathrm{~cm}$ in the weft. Threads were coarse, $\mathrm{S}$ twist, and medium spun with 12 warps per $\mathrm{cm}$ by 8 wefts per $\mathrm{cm}$. The rib pattern was $7 \mathrm{X}-2-7 \mathrm{X}-2-7 \mathrm{X}$ with a $9 \mathrm{~cm}$ repeat, but only repeated 3 times on this portion of the shroud.

Also from 2009, Burial NE \#66 layer 6 was of fine linen thread, basket weave with ribs in a $6 \mathrm{X}-2-6 \mathrm{X}-2-6 \mathrm{X}$ pattern. There was also a handkerchief as part of the face bundle measuring $24 \mathrm{~cm}$ in the warp direction by $30 \mathrm{~cm}$ weft.

Burial NE \#67 from the 2009 season had several layers of un-dyed basket weave linen shrouds with a $6 \mathrm{X}-2-6 \mathrm{X}-2-6 \mathrm{X}$ pattern. Threads were fine, single ply, S twist, soft spun with counts of 18 warps and 12 wefts. The rib pattern began $4 \mathrm{~cm}$ from the fringe with pattern repeats $8 \mathrm{~cm}$ apart and then widening to 12 and $15 \mathrm{~cm}$ apart. These burials are only a few examples of the numerous appearances of this rib pattern in burial shrouds and wrappings. There are a variety of combinations of this X-2-X-2-X pattern making each shroud unique.

Continuing to use the 2009 season as an example, 66 complete burials were discovered in the northeast portion of the 190/200 N 30/40 E area at depths between $60 \mathrm{~cm}$ and $250 \mathrm{~cm}$. Thirty-three burials have between 1 to 11 layers of basket weave linen with the X-2-X-2-X pattern. There were approximately 26 skeletalized burials with few, if any, fragments of textiles to study, and there are a few whose analysis is yet to be integrated into our database for use in studies.

It is possible this particular style of weaving was unique to a local workshop in the area of Fayoum. ${ }^{11}$ More research is needed to come to any definite conclusion. Yet some of the burial cloths are of lesser quality with uneven weaves and aberrations in the pattern, which could indicate the existence of a small cottage-industry consisting of individuals who wove textiles outside of a larger, more regularized industry, but rather in their homes. A tradition of weaving could have been passed along multi-generationally in such a setting.

The search continues to find comparable textiles in other museum collections that clearly correspond to the ones with the X-2-X-2-X rib pattern found at Fag el-Gamous. Efforts to communicate with other textile analysts from different excavations, especially in the Fayoum, are ongoing, in an attempt to discover the extent of the use of this specific weave pattern. One small fragment [page 191] pictured in the Masada IV publication of the Yigael Yadin Excavations from 1963-1965 shows a similar three-rib pattern, but it is of plain weave and not a

${ }^{11}$ For more on workshops in this area see the article on the history of the Fayoum, Seila and Fag el-Gamous in this volume. 
large enough fragment to suggest any repeat. ${ }^{12}$ Another fragment with a rib pattern to consider is from the Katoen Natie collection in Antwerp, Belgium. It is a half-basket weave linen piece with colored wool pile-weave ${ }^{13}$ decorations illustrating a lamp stand and two ankhs on either side of the lamp. ${ }^{14}$ It is dated (with 95.4\% probability) between $210-390$ AD. ${ }^{15}$ There are at least two X2-X-2-X type of weft rib repeats in the linen ground and within the wool design. Still, at this point it seems that while the X-2-X-2-X pattern is common at Fag el-Gamous, it is not as common in other areas. As the study of weaving patterns in antiquity expands, we will be better able to make comparisons that will refine this picture.

\section{Jewelry}

While the majority of burials do not have jewelry associated with them, it is still one of the more common kinds of grave goods found in the cemetery. For example, in a sample of 336 burials, only 77 (23\%) had any kind of grave goods. Of these, 12 (15.5\% of burials with grave goods, $3.5 \%$ of all burials in the sample) had jewelry. Pottery $(10 \%$ of the total burials in the sample) is the only more common kind of grave good interred with burials.

Jewelry could consist of beads (typically composed of glass, faience, clay, or shells), metal, leather, or combinations of these materials. Less commonly wooden, bone/ivory, ${ }^{16}$ or stone objects were part of burial jewelry. We have found a number of bracelets that are simple rings of metal, often consisting of two or three bands. We have been able to test the chemical make-up of several metal pieces of jewelry using an XRF analysis. These objects are predominantly [page 192] copper, with small amounts of zinc, iron, tin, arsenic and palladium also present. This is fairly similar to the composition of bronze.

In a sample of 33 pieces of jewelry stored at the Kom Aushim storage magazine, 13 $(39 \%)$ had metal objects, with 7 of those consisting only of metal. 10 pieces of jewelry (30\%) had glass ${ }^{17}$ (most frequently in the form of beads), with 3 of those being pieces of jewelry that consisted only of glass besides whatever material had been used to string them together. $9(27 \%)$ had faience as part of the piece, with one consisting of only faience. ${ }^{18} 6(18 \%)$ contained wooden objects, with 2 of those pieces of jewelry consisting solely of wood besides whatever kind of

\footnotetext{
${ }^{12}$ Avigail Sheffer and Hero Granger-Taylor, "Masada IV," The Yigael Yadin Excavations 1963-1965 Final Reports (Jerusalem: The Hebrew University of Jerusalem, 1994), 174.

${ }^{13}$ For an illustration of pile weave, see Elisabeth Grace Crowfoot, Qasr Ibrim: The Textiles from the Cathedral Cemetery (London: Egypt Exploration Society, 2011), 13.

${ }^{14}$ Antoine De Moor, 3500 Years of Textile Art (Tielt: Lannoo Publishers, 2009), 142-143

${ }^{15}$ Ibid.

${ }^{16}$ In small, aged, worked pieces such as these, we cannot tell whether the objects are of ivory or bone. In such cases it is standard and most transparent to refer to the pieces as bone/ivory. See Olga Krzyszkowska and Robert Morkot, "Ivory and related materials," in Ancient Egyptian Materials and Technology, Paul T. Nicholson and Ian Shaw, eds. (Cambridge: Cambridge University Press, 2000), 321. If these objects are ivory, they would most likely be hippopotamus ivory. See Ibid., 326-27.

${ }^{17}$ Glass at this time period was most frequently what is known as natron glass, as opposed to earlier time periods that used plant ash more heavily in their construction. See Julian Henderson, Ancient Glass, an Interdisciplinary Exploration (Cambridge: Cambridge University Press, 2013), 92-98.

${ }^{18}$ Faience is perhaps the earliest synthesized material, and is a very early forerunner to glass. See Ibid., 14. Faience was used in Egypt as early as $4000 \mathrm{BC}$ and continued to be used throughout Egyptian history.
} 
material had been used to string the wood. Additionally, $6(18 \%)$ had leather delicately carved or woven into part of the jewelry, but most often as the material which held the jewelry together. Leather does not survive as well as the other kinds of jewelry mentioned thus far, so it is quite likely that it was used at a much higher rate than these statistics reflect. Most commonly, the leather was braided in some way. Leather was always found used in combination with other materials. There were also $6(18 \%)$ that used clay, usually in the form of beads. Clay was also always used in combination with other materials. Bone/ivory was always used in combination with other materials, and was found in $3(9 \%)$ jewelry pieces. Yarn was used to string or tie together $3(9 \%)$ pieces of jewelry. Stone and shells were both used in $2(6 \%)$ jewelry items and always in combination with other materials.

It should be noted that this survey of materials used in jewelry is only a small sample. A much larger sample would be more statistically significant. It is hoped that in the future a close study of field books and objects from this excavation and similar cemeteries will yield a more detailed study of jewelry in the Roman Fayoum. Still, this small collection provides a useful snapshot of the kinds of materials used to make jewelry in this area of the Fayoum. Even with this, a greater depth of understanding can be gained by examining in detail a few specific pieces of jewelry from the cemetery. ${ }^{19}$

[page 193]

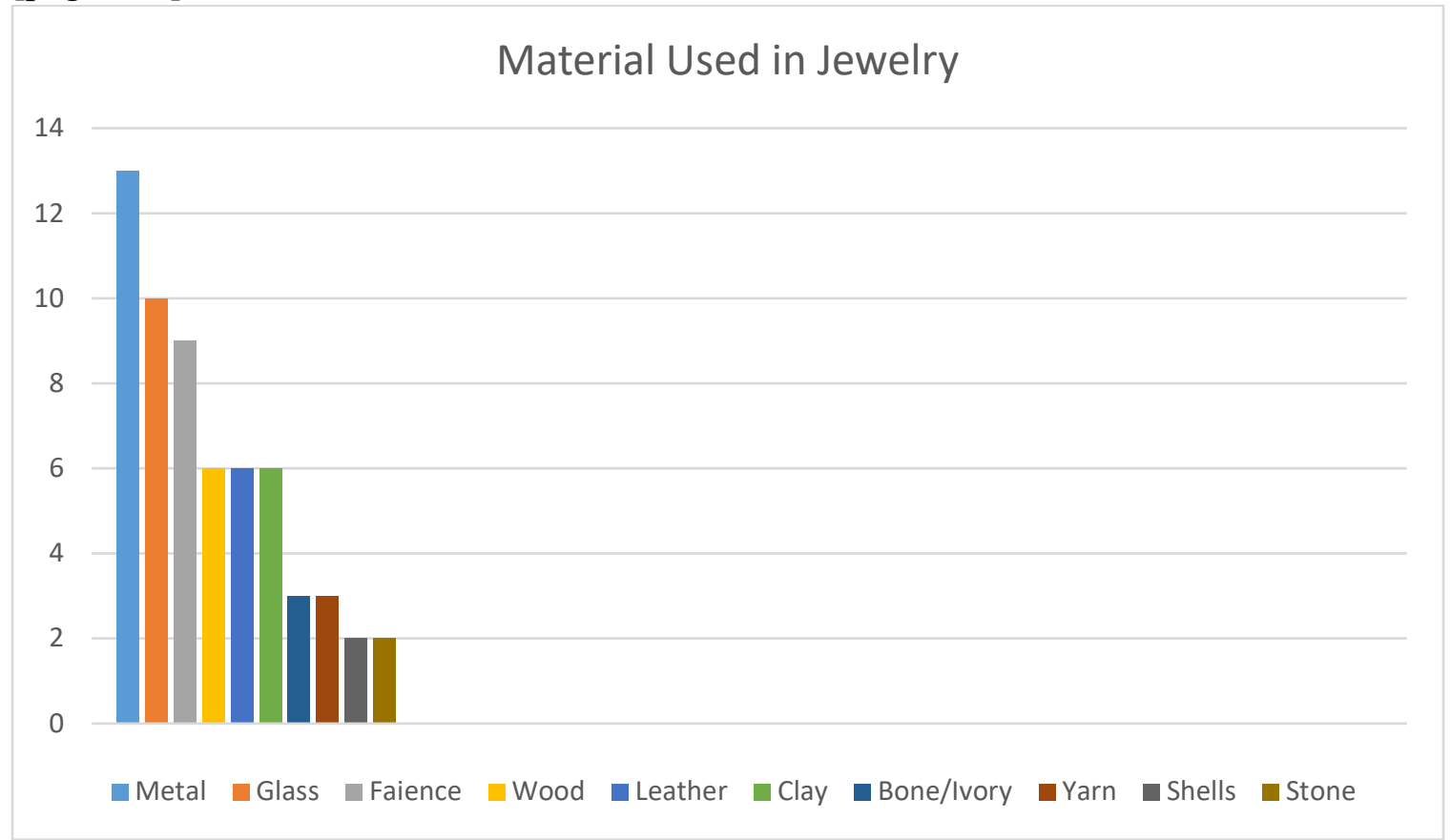

${ }^{19}$ The jewelry of these two burials were discussed in an earlier article, which was coauthored by Joyce Y. Smith, one of the coauthors of this article. For the article see Joyce Y. Smith, Kristin South, C. Wilfred Griggs, and Giovanni Tata, "Jewelry and accessories from two Christian burials from Fag el Gamous Cemetery in Fayum Region, Egypt," in Dress accessories of the 1st millennium AD from Egypt: Proceedings of the 6th conference of the research group 'Textiles from the Nile Valley' Antwerp, 2-3 October 2009, Antoine De Moor, Cäcilia Fluck, and Elisabeth Ehler, eds. (Tielt, Belgium: Lannoo, 2011), 204-219. Here we use some of the information from that earlier article, but we use it in a different way for a different purpose. We are grateful for the work done by our colleagues as represented in their article. 
While the two burials we now examine are from the sand cemetery and thus are, in large measure, from the "common man" by definition, the jewelry found with them is not common. This is partially because jewelry among these burials is uncommon overall and partially because among the small number that have jewelry, many have simple pieces (such as a band of metal forming a bracelet) that are informative, but not as flashy as other types of jewelry. Here we discuss two burials that seem to be common in most respects, yet are unusual in their jewelry. They also both had impressive textiles.

We first examine burial 190/200 N, 30/40 E, Southeast quadrant, \#44, found at a depth of $152 \mathrm{~cm}$ (hereafter just referred to as burial 44). The burial was clustered with three other adult burials, lying directly beneath one of them. Burial 44 was a brown-haired female who passed away at about age 18 . She was about 5 feet 2 inches tall $(155 \mathrm{~cm})$. While we cannot date this burial precisely, its depth suggests that it was interred somewhere around the material cultural height of the imperial Roman era, roughly between 200 and 400 AD. Its outer shroud was linen with a plain tabby weave with $7 \mathrm{~cm}$ bands of purple ${ }^{20}$ wool [page 194] woven over every four warps. These bands were separated by three white linen threads. The purple bands extended from the face and head of the burial to its feet. A loop fringe was also part of the shroud. The shroud was then secured by the use of the kind of red and white ribbon that is common at the cemetery. They were wrapped in a diagonal, rhomboid pattern, which is also common.

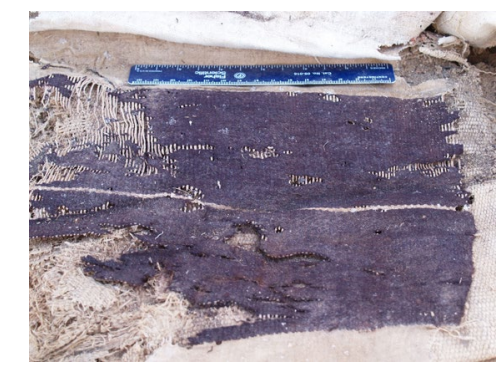

Figure 8.3: Purple "hue" weft bands from burial 44. Photograph by Joyce Y. Smith

A bead necklace was immediately apparent as the burial was uncovered. It was located under her chin and extending up to her right shoulder, which is where all of the beads were located. The beads were strung on braided leather strips. While the leather had largely disintegrated so that we cannot tell the exact original form of the necklace, the surviving arrangement makes it seem that it was a multi-strand necklace.

\footnotetext{
${ }^{20}$ For more on the use of purple in the burials of Fag el-Gamous, see the paper on purple dye in this volume. While this particular textile was not among those we were able to test, based on the trend of purple dye at Fag el-Gamous, we assume the purple thread in burial 44 was not Tyrian purple.
} 


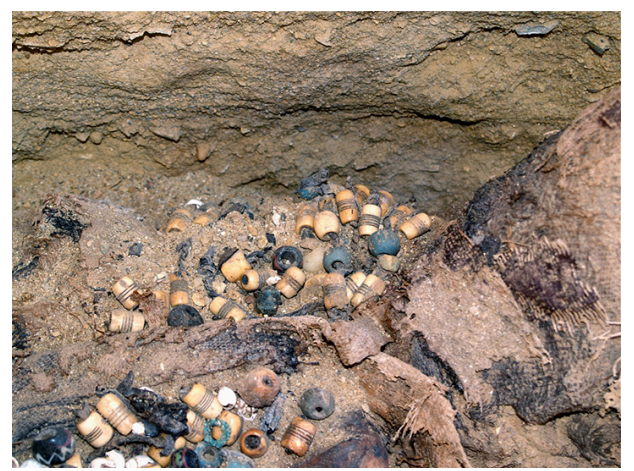

Figure 8.4: Head of burial 44 with beads in situ on chest and right shoulder. Photograph by Joyce Y. Smith

The necklace consisted of a striking number and variety of beads. The beads were strung on narrow $(.2-.3 \mathrm{~cm})$ braided leather strips. At intervals, a single strip looped over the outside of the bead to separate it from the next bead and hold it in place. [page 195]

There were 78 bone/ivory beads, many of which had bands incised around the belly of the bead. Bone/ivory is carved into shape much as one would carve wood. The consistency and uniformity of the 78 barrel shaped ivory/bone beads indicates that they were probably turned on some kind of lathe after having had a hole drilled in them. Some of the beads have no incised lines around their belly, others have 2 or 3 incised belly lines. Lathe work is also evident in these precise, parallel, incised lines seen on the belly of 58 of the beads. Dyes and paints were sometimes used on bone/ivory pieces, however the decorative lines on these beads are blackened because they are dirt filled. When the dirt was removed there was no indication of dye or paint remaining in the incised lines.

There were also 21 glass beads, most with colored stringer designs in wave patterns, along with 25 small white shells and a small metal bell with a shell clapper. There was also a small metal ring ( $1.3 \mathrm{~cm}$ in diameter) and a larger metal ring $(3.8 \mathrm{~cm}$ in diameter). These metal rings were similar to bronze in their chemical makeup. As the beads were strung on the leather strip, they were separated at intervals by a single strip looped over the outside of the bead. These beads are of the style known today as "stringer beads."

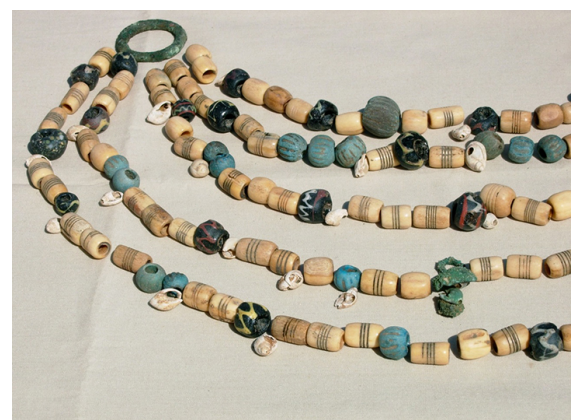

Figure 8.5: Beads from the necklace of burial 44 arranged by the excavation team. Photograph by Joyce Y. Smith

[page 196] 
The shells on this necklace appear to be White Nassa or Dove shells with holes drilled artificially. ${ }^{21}$ Several different gastropod (a kind of mollusk) shell beads were used, including discoidal, depressed, and elongate shapes. These are found both in the Red and Mediterranean Seas.

The faience beads are similar to those used in Egypt from its earliest history. ${ }^{22}$ It is formed in a manner very similar to glass, except that heat is applied later in the process. ${ }^{23}$ Silica, from ground quartz or sand crystals, was combined with sodium and lime and then was mixed with other minerals, such as calcium, magnesium oxide, potassium oxide, and copper oxide. The copper oxide, combined with varying amounts of other elements, is what causes the [page 197] turquoise or blue coloring. ${ }^{24}$ Because of lower amounts of soda and lime than in glass, the silica does not melt completely, and thus it does not become glass, but rather small enough amounts of glass are formed to bind the rest of the material together in a hardened and glossy state. ${ }^{25}$ As a result, Faience objects are molded in a clay-like state, and are then fired. ${ }^{26}$ Faience could be molded by hand, molded in a form, created with a core that was burned away, or occasionally larger objects could be formed on a wheel, though this was much less successful than with ceramic clay. ${ }^{27}$ As with the glass beads (see below), the faience beads in this necklace appear to have been core formed.

Some of the faience beads of Burial 44 are plain with no design, but most are in the popular, frequently found ribbed beads in melon form. Compared to other specimens of melon beads, these are not of the highest quality faience work, as indicated by the sometimes rough and un-evenness of the exterior glaze. They were predominantly hand formed of ceramic material employing the efflorescence method of glazing. Coloration is evenly distributed inside and outside the bead and appears to be integral with the body of the bead. Subtle color differences indicate that the beads were from at least two separate batches of paste mix and firing. The shine and texture of two of the beads indicate they were glazed by a different technique; either by cementation or the application method.

Three faience beads show signs of being formed with a mold. One exhibits unusually even, fine ribbing while the others appear to be hand formed with wide, somewhat random pressed ribs. Two of the plain beads are very smooth and unusually round indicating they may

${ }^{21}$ A. Lucas, revised by J. R. Harris, Ancient Egyptian Materials and Industries (London: Histories and Mysteries of Man LTD, 1962).41

22 Paul T. Nicholson, "Faience Technology," in Willeke Wendrich, ed., UCLA Encyclopedia of Egyptology (Los Angeles: http://digital2.library.ucla.edu/viewItem.do?ark=21198/zz0017jtts), 2.

23 Ibid., 1-2.

${ }^{24}$ Ibid., 2; Paul T. Nicholson and Edgar Peltenberg, "Egyptian Faience," in Ancient Egyptian Materials and Technology, eds. Paul T. Nicholson and Ian Shaw (Cambridge: Cambridge University Press, 2000), 177-180. See also Carolyn Riccardelli, "Egyptian Faience: Technology and Production," The MET Essays, https://www.metmuseum.org/toah/hd/egfc/hd egfc.htm; and Joshua J. Mark, "Faience," Ancient History Encylopedia online, https://www.ancient.eu/Faience/.

${ }^{25}$ Nicholson, "Faience Technology," UEE, 2.

${ }^{26}$ S. La Delfa, V. Formisano, and E. Ciliberto, "Laboratory Production of Egyptian Faiences and their Characterization," Journal of Cultural Heritage 9/1 (2008): 113-116.

${ }^{27}$ Nicholson, "Faience Technology," UEE, 2-3; Riccardelli, "Egyptian Faience," and Mark, "Faience." 
have been pressed into a mold. It is possible, however, for a highly skilled worker in hand formation to obtain such roundness without the use of a mold. As was noted above, core forming was probably the most common method for forming most of the faience beads. ${ }^{28}$ [page 198]

The glass beads of this burial appear to also be made by a core-forming method. Core forming glass-work was the forerunner of what is now called "lampworking." This method can also be referred to as the wound-bead flamework technique, or torch working. This is now done with a single concentrated heat source such as a blowtorch, but during the Roman era the glass was heated using a conical shaped furnace with vents. It is one of the earliest known glassmaking techniques. $^{29}$

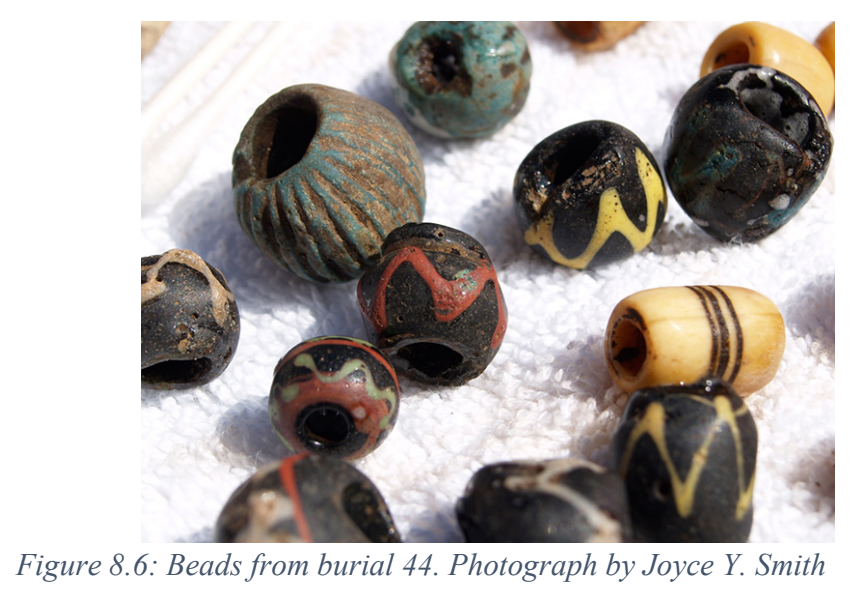

The method of making these core-formed stringer beads has not changed dramatically from the Roman era until now, though, as noted, more sophisticated tools are available today. In this method, glass "rope" rods or cane (cane is pencil sized, while stringers are very thin cane) drawn and formed previously are softened in the heat of the conical furnace to a molten state and are then wound around a heat resistant metal core axis or mandrel (also called a pontil) coated with a bead-release material (clay tempered with talc anciently.) The [page 199] glass bead is then heated several times as more layers of glass "rope" are wound around the mandrel to build it up to the desired size. Once the glass has cooled the core is removed, leaving a hollow spot inside the glass bead.

The successive applications of heat and layers of glass introduces the opportunity for decorating the piece. As the glass makers pull a point out from a hot gob of glass on a pontil rod with tweezers or a hook needle, the tip of the point is touched to another ball of glass on another pontil. Both rods are kept in the flame while working. The point sticks and a thread of glass

\footnotetext{
${ }^{28}$ William M. F. Petrie, The Arts and Crafts of Ancient Egypt, (Twickenham, UK, Senate, an imprint of Tiger Books International PLC, 1996), 119, was the first to propose this method.

29 "Glassmaking Technique: Core-Formed Glass," J. Paul Getty Museum, accessed December 1, 2017, http://www.getty.edu/art/collection/video/142904/glassmaking-technique:-core-formed-glass/. Also see Henderson, Ancient Glass, 223-27 and 232-33; and Axel von Saldern, “Ancient Glass," Boston Museum Bulletin 64/335 (1966): 6.
} 
"stringer" is pulled from point to point, leaving zig-zag lines around the sphere. The thread is broken or melted off and the pattern is melted flat to the more massive surface of the sphere.

In an attempt to fully understand the process, Professor Brian Christensen and his student, Noah Coleman, enacted a bead making process comparable to ancient methods. Employing kilns to melt the raw glass in ceramic crucibles, they drew out the molten glass, pulling it into colored glass rods (cane). Just as was described above, they then cut it into useable lengths before it was completely cooled and hardened. Instead of the clay and dung based (or possibly copper wire) mandrel (or core) that was probably used anciently, ${ }^{30}$ they employed mandrels made of stainless steel, coated with a bead release of crystalline silica and alumina. Rather than using cone furnaces, they used a propane-oxygen blowtorch at 2500 degrees Fahrenheit to soften the cane and then applied one layer of glass "rope" at a time, adding more layers until the bead reached the desired size. Decorations were applied with thin glass stringers of various colors. Doing this, they were able to reproduce beads that were very similar to those found with burial 44 .

The glass stringer beads of this burial seem to be in line with techniques and colors known to be used in Coptic Egypt. These beads were the result of practices that had originated in Egypt and then spread throughout the Mediterranean and Fertile Crescent much earlier, and were in use in both Greece and Rome, ${ }^{31}$ and were particularly flourishing in Egypt at the time. ${ }^{32}$ The Fayoum [page 200] had Roman, Greek, Egyptian and Jewish populations. These were all cultures in which this kind of glass working had spread. Thus it is not surprising to find this type of glass work present at Fag el-Gamous.

The glass beads from burial 44 all had a black glass base bead form with white, green, blue, red and yellow lampworking. Some of the beads exhibit applied designs that were not heated to a point where the decoration fully integrated into the black base, resulting in the color design staying partially on the surface, creating a texture. Others were heated and melted into the black base completely creating a smooth, integrated design.

The glass beads are colorful and beautiful, but in some ways appear to not reach the craftsmanship one would expect from the high art achieved during the height of Roman glass production, especially in Egypt at the time. ${ }^{33}$ The seeming defects in the beads suggest the possibility that the beads were made locally, not at a center of production that could achieve high

\footnotetext{
${ }^{30}$ While copper wire was used in some places, in Egypt the most common core was a mixture made primarily of clay and dung. See Paul T. Nicholson and Julian Henderson, "Glass," in Ancient Egyptian Materials and Technology, Paul T. Nicholson and Ian Shaw, eds. (Cambridge: Cambridge University Press, 2000), 202-03. See also Albert Neuburger, The Technical Arts and Sciences of the Ancients, Henry L. Brose, trans. (London: Kegan Paul Press, 2003), 155-56.

${ }^{31}$ Frederic Neuburg, Ancient Glass, Michael Bullock and Alisa Jaffa, trans. (Toronto: University of Toronto Press, 1962), 18-20.

${ }^{32}$ Ibid., 30-32. See also Albert Neuburger, The Technical Arts and Sciences of the Ancients; Frederic Neuburg, Glass in Antiquity, R. J. Charleston, trans. (London: Ranking Brothers Limited, 1949), 8-16; and A. Lucas, Ancient Egyptian Materials (New York: Green \& Co., 1926), 44.

${ }^{33}$ During this era, Egypt became a serious producer of glass in both quantity and quality. This was so much the case that Roman emperors placed high taxes on Egyptian glass to offset the cheapness created by the quantity of their desirable glass. See Sandra Davison, Conservation and Restoration of Glass (Oxford: Elsevier Science, 2003), 23-24.
} 
artisanship. ${ }^{34}$ The texture of the exterior of the glass exhibits symptoms of "sick glass," or a composition slightly deficient in calcium oxide (lime), that over a long period of time can cause visual defects in the glass, including opaqueness and an internal web of fine lines known as crizzling.

At the same time, core forming can be very sophisticated when feathering is applied to beads and vases. In many cases the opaqueness is intentional. It is possible that the apparent crizzling and opaqueness should not be viewed as a composition defect, instead they could be an intentionally created visual effect. The wavy patterns were also often part of the aesthetic of glassware. This kind of opaque and crizzling patterning created an organic look that was employed in Roman and later Venetian core formed glass. ${ }^{35}$ For example, Venetian traditions use some of the same opaque feathering and stringer techniques on blown and solid glass. Thus it could be that the beads were of higher craftsmanship and their appearance is fully intentional. [page 201]

Burial \#13 of 180/190 North, 40/50 East, Southwest quadrant (hereafter referred to as burial 13) was uncovered in 2003 and analyzed during the 2007 dig season. The burial was an adult female, about five feet and three inches tall $(162 \mathrm{~cm})$. Again, we cannot provide a precise date, but the burial depth of $60 \mathrm{~cm}$ suggests she was interred somewhere around the Byzantine era.

The textiles and accessories of Burial 13 are extraordinary. While textiles are not the focus of this examination, it is worth noting that this woman had been wrapped in several layers of linen shrouds. Most of those were coarse linen ${ }^{36}$ of simple weave, but one layer was a yellow weft faced woolen piece. This tunic had blue, yellow, green and red tapestry designs, ${ }^{37}$ using slit, dovetail, and interlocking weaving methods. ${ }^{38}$ A woolen sprang head covering consisting of red with yellow and green trimmings was held in place by hairpins, one made of gold and the other of ivory/bone. Brilliant red strands of wool bound her feet, and a wool loop of cordage was on her face, looping down to her chest and abdomen. The same red wool also encircled her pelvis.

On the upper left arm, fragments of ivory/bone bracelets remained. These fragments were pieced together to form four full bracelets with a portion of a fifth remaining. The bracelets were clasped with a small metal wire fastener. On this same arm a partial metal bracelet was also found.

\footnotetext{
${ }^{34}$ On the uniformity of glass making in production centers see E. Marianne Stern, "Glass Production," in The Oxford Handbook of Engineering and Technology in the Classical World, John Peter Oleson, ed. (Oxford: Oxford University Press, 2008), 520-21.

${ }^{35}$ On Venetian glass, see Rosa Barovier Mentasti, "Glass and Glassmakers from the Renaissance to the Present Day," in Glass Throughout Time, History and Technique of Glassmaking from the Ancient World to the Present, Rosa Barovier Mentasti, Rosanna Mollo, Patrizia Framarin, Maurizio Sciaccaluga, and Anna Geotti, eds. (Torino: Skira Editore, 2003), 26-28.

${ }^{36}$ Ancient Egyptian terms for linen include terms for different grades of linen. The fineness of the linen is determined by thread count, similar to sheets and other kinds of cloth in our day. From both texts and archaeological data it is clear that "smooth" or what is called today "coarse," linen was by far the most common. See Rosalind Hall, Egyptian Textiles (Buckinghamshire: Shire Publications Ltd., 2003), 9.

${ }^{37}$ Tapestry designs in tunics were very common at the time. See Ibid., 33.

${ }^{38}$ Vogelsang-Eastwood, "Textiles," 275.
} 


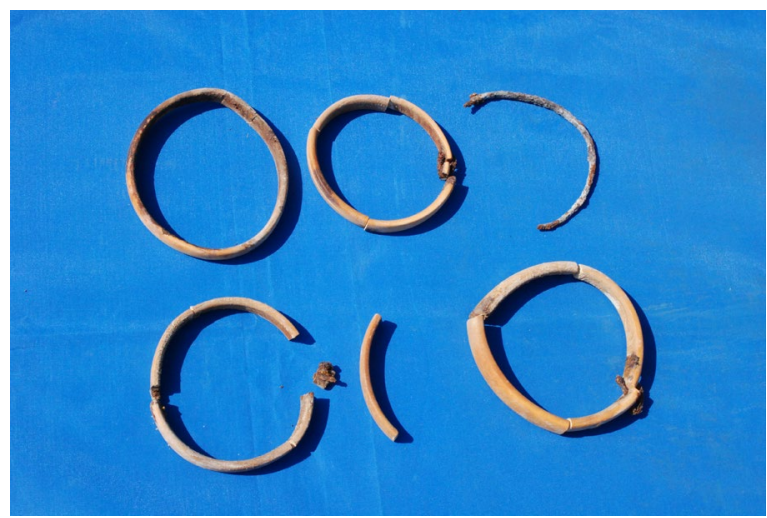

Figure 8.7: Ivory/bone bracelets and fragment of a metal bracelet from burial 13. Photograph by Joyce Y. Smith.

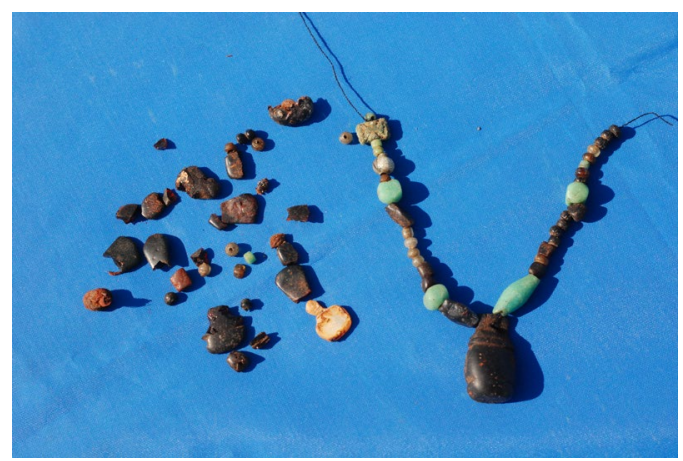

Figure 8.8: A reconstruction of the pattern from the non-intact necklace of burial 13. Photograph by Joyce Y. Smith

There was more jewelry on this unusual burial. About her neck, lying on her chest, were the remains of three necklaces. Two necklaces were intact enough to present them as they were found. The beads and amulets were strung on thick two-ply red wool strands, with knots made in these strands between each bead in order to provide spacing, though the holes for many of the beads were large enough they could slip over the knots.

The most common piece on both of these necklaces was white beads, tubular in shape with ribbing stretching along their length. The ribbing is probably natural, for these beads are made from Scaphopoda dentalium, or tusk shells, which are typically ribbed in their native state.

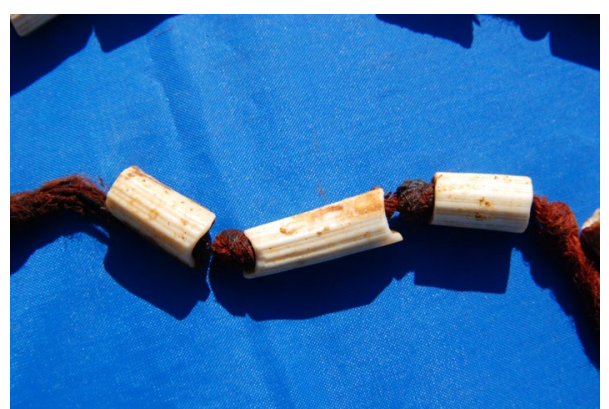

Figure 8.9: Shell beads and yarn from one of the intact necklaces of burial 13. Photograph by Joyce Y. Smith 
The large, beautiful red pendants that were the focal point of these necklaces were both made of glass, which is only apparent when held up to the light. Such light exposure also reveals potential crizzling. Alternatively, the cracking could be due to a defect in what is known as "fit." Fit has to do with [page 202, figures 8 and 9] [page 203] the coefficient of expansion in two kinds of glass. If one type expands or shrinks more than the other, cracks appear. Another possibility is thermal shock. Compressing glass between two surfaces could chill the exterior and crack it without breaking the whole piece if it were placed back in moderate heat to anneal quickly enough. Melting the surface would cure this, but it could have been put away to anneal without noticing.

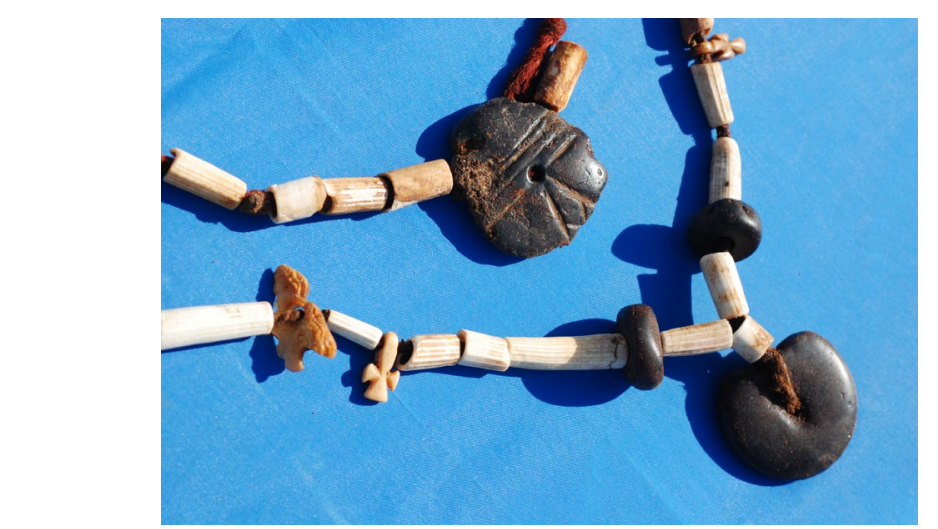

Figure 8.10: The two intact necklaces from burial 13. Photograph by Joyce Y. Smith

The red glass amulets are probably pressed into their basic shapes on a marver (a heat resistant heavy metal sheet) rather than into a mold. Red glass is particularly difficult to produce. The colorant used most often was copper. Red glass has probably been under-recorded by Egyptologists due to its tendency to discolor to green. ${ }^{39}$ These amulets have an appearance consistent with copper-red. Gold and selenium are also oxides that produce the color red. Though copper seems likely, gold cannot be ruled out since the use of gold can produce a similar look (because copper and gold have a very similar colloidal absorption rate), and is an oxide producing a red not likely to discolor [page 204] into green. ${ }^{40}$ Iron can vary from red to green, ${ }^{41}$ but seems less likely in this case. Copper oxide causes this effect frequently, according to reduction or oxidation atmosphere.

\footnotetext{
${ }^{39}$ Paul T. Nicholson and Julian Henderson, "Glass" in Ancient Egyptian Materials and Technology, Paul T. Nicholson and Ian Shaw, eds. (Cambridge: Cambridge University Press, 2000), 199.

${ }^{40}$ James E. Shelby, Introduction to Glass Science and Technology (Cambridge: The Royal Society of Chemistry, 1997), 205-206.

${ }^{41}$ Ibid., 201-202, 204.
} 


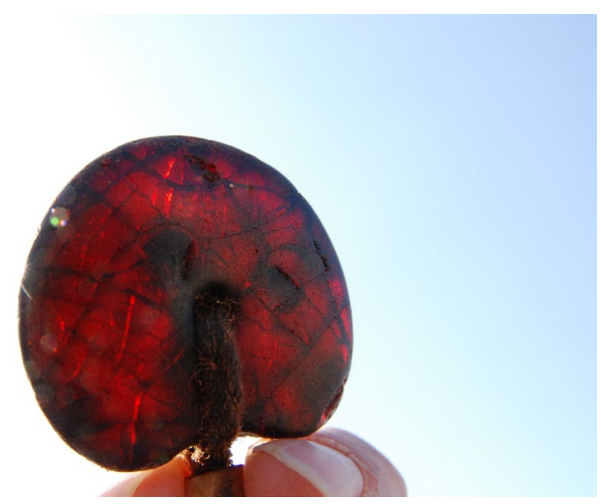

Figure 8.11: One of the glass medallions from a necklace of burial 13. Photograph courtesy of Joyce Y. Smith

Besides the beads, there are some other interesting pieces on these necklaces. Strung in the middle of one of these necklaces were two carved ivory/bone crosses. ${ }^{42}$ Additionally, a brilliantly glazed faience amphora bead was present. This glazing was probably produced by cementation or application. The remains of what could be a kiln stilt mark that could be made during firing may suggest that the application method of glazing was employed. Another piece, which appears to be made of resin, seems to be either a fish or a bird. This same necklace contained two un-incised red glass beads that are quite large.

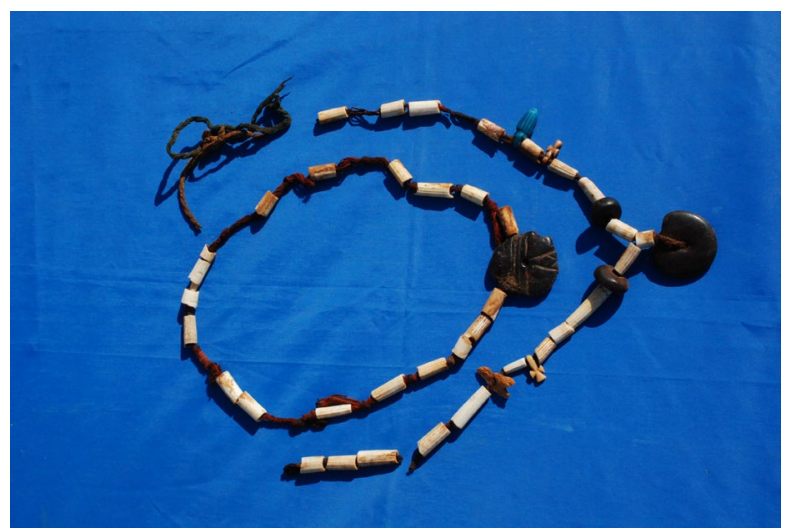

Figure 8.12: The two intact necklaces of burial 13. Photograph by Joyce Y. Smith

The third necklace contained the broken remnants of several red glass pieces. There was also an unbroken piece of red glass in a fan or tear drop [page 205, figures 12 and 13] [page 206] shape which had three horizontal lines scored across the top. Similar to the red glass used in the other necklaces, currently it is not immediately apparent that this piece is glass. It looks more like stone until it is held up to the light. Before being deposited in the sand for thousands of years, its glass nature would have been more apparent. This same necklace also contained several small, colored glass beads. Some of these beads were mock turquoise. Shell and faience beads were also included. These beads were decorated by opposing triangles. Pomegranate beads and a

\footnotetext{
${ }^{42}$ For a discussion of the possible meanings of these figures and others in the jewelry presented herein, see the excellent discussion on this topic in Smith, et al., "Jewelry and Accessories."
} 
lotus seed vessel pendant made of high quality faience are present. The shell beads are Scaphopoda, a mollusk, also known as tusk shells. They naturally develop in the tubular form used in this necklace, complete with the "fluted" exterior. This necklace, as with the others, is a beautiful piece of jewelry. Together, the three necklaces together formed a striking appearance.

We hope, in the future, to compile partial biographies of a number of individuals from this region, using textual, biological and other archaeological materials, so that we can more fully tell the stories of at least some of these individuals. While this will require a considerable investment of time and resources, we believe the stories of ancient lives revealed this way will be worth the investment. In this article we are not attempting to create archaeobiographies, but rather are attempting to use a few specific details to help paint the broad brush stroke background pictures that will help us understand the conglomeration of people from this place better. In our quest to understand the lives and deaths of the common man in the Fayoum of Roman Egypt, it is worth looking at that which is most common among them, as well as that which is unusual even among the common. It helps us glimpse the accessories of life and see how they viewed and valued existence for the dead. The plain textiles discussed above are among the most common element of the burials of the majority of people in the Fag el-Gamous area, though the particular style seems unusual outside of this area. Most of the textiles used in burial are not uncommon, yet they represent a significant amount of resource investment for the common class. At the same time, even these commoners had that which was unique about them, as is illustrated in the beautiful, singular, and unusual jewelry found on just a few of these common burials. While the possessors of the jewelry described herein did not receive an elite burial, they clearly had access to some degree of wealth. Furthermore, those who buried them must have felt that these objects were integral to the deceased, enough so that they were willing to bury with them objects of some monetary worth. All of this is evidence that even the common majority were each individually unique.

[page 207] 